\title{
Shining a Light on Wastewater Treatment with Microalgae
}

\author{
John J. Kilbane II ${ }^{1}$ \\ Received: 28 July 2021 / Accepted: 25 November 2021 / Published online: 12 January 2022 \\ (c) King Fahd University of Petroleum \& Minerals 2021
}

\begin{abstract}
Microalgae can produce biofuels, nutriceuticals, pigments and many other products, but commercialization has been limited by the cost of growing, harvesting and processing algal biomass. Nutrients, chiefly nitrogen and phosphorus, are a key cost for growing microalgae, but these nutrients are present in abundance in municipal wastewater where they pose environmental problems if not removed. This is not a traditional review article; rather, it is a fact-based set of suggestions that will have to be investigated by scientists and engineers. It is suggested that if microalgae were grown as biofilms rather than as planktonic cells, and if internal illumination rather than external illumination were employed, then the use of microalgae may provide useful improvements to the wastewater treatment process. The use of microalgae to remove nutrients from wastewater has been demonstrated, but has not yet been widely implemented due to cost, and because microalgae derived from wastewater treatment has not yet been demonstrated as a commercial source for value-added products. Future facilities are likely to be called Municipal Resource Recovery Facilities as wastewater will increasingly be viewed as a resource for water, biofuels, fertilizer, monitoring public health and value-added products. Advances in photonics will accelerate this transition.
\end{abstract}

Keywords Wastewater $\cdot$ Microalgae $\cdot$ Anaerobic digestion $\cdot$ Photodecarboxylase $\cdot$ Nutrient recycling $\cdot$ Biofilms $\cdot$ Internal illumination · Photobiology $\cdot$ Optical fibers $\cdot$ LED

\section{Introduction}

It is proposed that the increased use of microalgae to treat wastewater can benefit both the treatment of wastewater and the production of biofuels and various products from microalgae. More specifically, it is proposed that internal illumination should be used to support the growth of microalgae as biofilms. The reasons for these suggestions are briefly stated below, followed by more detailed discussions of the various topics mentioned.

Why should microalgae be used in wastewater treatment?

- More rapid, complete and economical removal of pollutants.

- Nutrient recycling Residual nitrogen and phosphorus in wastewater effluent creates environmental problems, while the cost of growing microalgae can be decreased by utilizing nutrients in wastewater.

Why should microalgae be grown as biofilms rather than as planktonic cells?

John J. Kilbane II

kilbane@iit.edu

1 Illinois Institute of Technology, Chicago, IL, USA
- Improved wastewater treatment By growing microalgae as biofilm, the retention of biomass is decoupled from the hydraulic retention time (HRT) allowing even microorganisms with cell generation times longer than the HRT to be retained and provide the amount of active biomass needed to treat wastewater as rapidly as possible.

- Biofilms are inherently more robust and can tolerate fluctuating environmental conditions, toxic chemicals and antibiotics.

- Decreased cost of harvesting and dewatering of biofilms as compared with planktonic cells.

Why should internal illumination be used rather than external illumination of photobioreactors?

- Improved efficiency Photoinhibition can be avoided, and only light wavelengths used by photosynthetic microorganisms are supplied.

- Facilitates the growth of biofilms.

- Can be used in turbid solutions.

- More flexible reactor design.

There is a high level of interest in developing biofuels as a replacement for fossil fuels, and microalgae have been viewed as a promising source of lipids for the production of 
biodiesel [1-4], or for the conversion of microalgae biomass to produce methane [5, 6], or ethanol [2, 4]. However, while an increasing list of value-added chemicals such as polyunsaturated fatty acids, carotenoids/pigments, antioxidants, biopolymers, and other nutraceutical and pharmaceutical compounds $[2,7,8]$ are now commercially produced from microalgae, the economical production of biofuels from microalgae is still an unrealized goal [9].

Cost is the main constraint limiting large-scale production of renewable fuels from microalgae [10], but another important limitation is nutrients [11, 12]. Not only is it costly to provide chemical nutrients to support microalgal growth, but the availability of phosphorus in particular could well become a limiting factor in the foreseeable future [6, 7]. By using microalgae to treat wastewater, the cost of growing microalgae can be reduced as the nutrients in wastewater, chiefly nitrogen and phosphorus, can be recycled and used by microalgae $[13,14]$. The application of microalgae to treat wastewater has primarily focused on polishing wastewater to remove nitrogen and phosphorus after the majority of organic contaminants have been removed, but some studies have demonstrated that microalgae can be used instead of the activated sludge process as the main treatment for the removal of organic and inorganic contaminants $[14,15]$. The cost of microalgae production can be decreased if wastewater is used as a source of nutrients, and the cost of wastewater treatment can be reduced through the use of microalgae by improving the efficiency of the process and through the production of value-added by-products $[9,10]$. While the utilization of nutrients present in wastewater can reduce the cost of growing microalgae, the avoidance of environmental problems due to nutrients in wastewater effluent provides an even more important reason to consider the use of microalgae to improve wastewater treatment.

Wastewater treatment challenges include land availability, cost and effectiveness [16]. Growing microalgae as biofilms, rather than as planktonic cells in solution, can facilitate the growth and harvesting of algal biomass and advances in photobiology can decrease the cost of growing microalgae, particularly as biofilms. The objective of this manuscript is to describe how photobiology can benefit wastewater treatment and lead to the development of a mature technology for the production of renewable energy and multiple biorefinery products from microalgae. The specific contribution to the literature made by this manuscript is to discuss how the diverse topics of wastewater treatment, microalgae, biofilms, internal illumination of photobioreactors, renewable energy, LEDs, photobiology, photoenzymes, materials science, artificial intelligence, robotics and engineering can all contribute to the development of future processes for the treatment of wastewater, recycling of nutrients and the production of bioproducts. Interdisciplinary research will be required to develop less expensive LEDs, inexpensive material suit- able for the internal illumination of photobioreactors, the maximization of illuminated surface area for the growth of biofilm, the integration of microalgae into wastewater treatment, nutrient recycling and the production of value-added products. Researchers in these areas may be unaware of the collaborative opportunities in the use of microalgae in wastewater treatment and increased communication to stimulate research is the goal. The use of microalgae to treat wastewater, the growth of microalgae as biofilms and the use of internal illumination in microalgae photobioreactors are not new concepts, but what is new is increased awareness regarding recycling nutrients from wastewater, rapid innovation with a variety of renewable energy technologies, new discoveries in photobiology, decreasing costs for LEDs, an increased use of robotic devices to automate processes and increased interest in developing circular economies. This field is ripe for innovation and cross-discipline collaboration, and a goal of this manuscript to promote an awareness of the challenges and opportunities. Wastewater should be viewed as a resource rather than as an expense $[17,18]$.

\section{Wastewater Treatment Overview}

Municipal wastewater treatment plants currently employ a two- or a three-step process $[19,20]$ as described in Table 1. The first step, primary treatment, consists of removing large particles of organic and inorganic material that can be removed by physical and mechanical processes such as gravity in settling tanks and by coarse filtration/screening. Secondary treatment most commonly employs aeration to promote the biodegradation of organic contaminants by microorganisms, principally bacteria, but also microalgae and fungi. The biomass of microorganisms produced as a consequence of the biodegradation of contaminants in wastewater is removed by gravity in settling tanks resulting in waste activated sludge and water of improved quality [19]. The water that has benefitted from primary and secondary treatment will still usually contain residual amounts of nitrogen and phosphorus in sufficiently high concentrations to result in ecological damage when discharged to the environment, so tertiary wastewater treatment is required to produce clean water that will not cause the eutrophication of rivers, lakes and oceans [21].

Eutrophication is the consequence of an excess supply of nutrients needed for the growth of microalgae and other microorganisms. The abundant nutrients result in the rapid and prolific growth of microbial biomass and the consequent depletion of oxygen due to the aerobic metabolism of microbes and the aerobic biodegradation of dead biomass. The concentration of oxygen is especially depleted in coastal areas adjacent to cities due primarily to the discharge of nutrients in wastewater and agricultural runoff such that more 
Table 1 Wastewater treatment and associated processes

\begin{tabular}{|c|c|c|c|}
\hline Process step & Description & Products & Volume \\
\hline Primary treatment & Physical and mechanical removal of solids & Cleaner wastewater & $100 \%$ \\
\hline Secondary treatment & $\begin{array}{l}\text { Aerobic biodegradation of organics creating biomass } \\
\text { (waste activated sludge) }\end{array}$ & Cleaner water, biomass & $100 \%$ \\
\hline Tertiary treatment & $\begin{array}{l}\text { Trace contaminant and nutrient removal through } \\
\text { creating biomass }\end{array}$ & Clean water, biomass, $\mathrm{CO}_{2}$ fixation & $99 \%$ \\
\hline Anaerobic digestion & $\begin{array}{l}\text { Solids from primary and secondary treatments are } \\
\text { microbiologically converted to biogas and residual } \\
\text { solids }\end{array}$ & Biogas energy, cleaner wastewater, residual solids & $1 \%$ \\
\hline Composting & $\begin{array}{l}\text { Residual solids from anaerobic digestion and/or } \\
\text { biomass are aerobically composted to produce } \\
\text { fertilizer }\end{array}$ & Fertilizer & $<1 \%$ \\
\hline Biomass utilization & Multiple products & $\begin{array}{l}\text { Animal feed, nutraceuticals, pharmaceuticals, lipids } \\
\text { for biodiesel, carbohydrates for ethanol, biogas } \\
\text { production, fertilizer }\end{array}$ & \\
\hline
\end{tabular}

than 500 oxygen minimum zones have been identified worldwide [22, 23]. This has resulted in serious reductions in fish populations, often impacting populations dependent on subsistence fishing. Increased $\mathrm{CO}_{2}$, temperature and nutrients have altered the ocean productivity, biodiversity and biogeochemistry [22]. Moreover, changes in ocean temperature and $\mathrm{pH}$ are mechanistically linked to oxygen concentrations, and modeling has shown that even if anthropogenic sources of pollution were completely stopped a further fourfold decrease in the oxygen concentration in the world's oceans will occur [24].

The International Water Association estimates that $80 \%$ of wastewater worldwide is discharged untreated into the environment [www.iwa-network.org] and the United Nations estimates that $55 \%$ of the world population is without safely managed sanitation [www.unwater.org]. Other studies [16, 25] estimate that $52 \%$ of global wastewater is treated to some degree, while $48 \%$ of wastewater is released, untreated, to the environment. It is not only the developing countries that need improved wastewater treatment, as the American Society of Civil Engineers gave the US wastewater infrastructure a grade of D + in 2017 [www.infrastructurereportcard. org], and about $66 \%$ of the energy content in wastewater is destroyed/wasted by current wastewater treatment technology [26]. Therefore, there is a huge opportunity for new technology that can treat wastewater more effectively and inexpensively, and use of microalgae and photobiology may provide appropriate new technologies.

\section{Current Status of Microalgae use for Wastewater Treatment}

A limitation of the activated sludge process is that while it removes the vast majority of organic contaminants, inorganic contaminants such as phosphorus and nitrogen are frequently present in the effluent at concentrations high enough to cause environmental damage/eutrophocation in downstream rivers, lakes and oceans [21]. Where microalgae are intentionally used to treat water today, it is almost exclusively as a polishing step to remove phosphorus and nitrogen, despite the fact that microalgae are capable of removing both organic and inorganic contaminants $[27,28]$. The use of microalgae to remove nutrients is not widespread and the resulting biomass is generally not harvested for beneficial use; thus, the use of microalgae to treat the entirety of wastewater and recycle nutrients for agricultural use is in its infancy [29]. Wastewater treatment plants currently are focused on treating waste rather than on making a product and the nutrients present in wastewater-derived biomass are not always recycled. Future wastewater treatment plants will be aware of the need for more energy efficient processes that not only remove contaminants, but also recycles nutrients to support agriculture, recovers energy in the form of biofuels and may also produce value-added chemicals derived from microalgae. Microalgae biomass produced at wastewater treatment facilities will most likely be processed offsite to obtain specialty chemicals, but the facilities of the future will be designed and operated to maximize nutrient and biomass recovery and recycling.

The reason that the microalgae industry is interested in combining wastewater treatment with the growth of microalgae is to reduce the cost of microalgae-derived products. The cost of growing, harvesting and processing microalgae currently prevents the use of microalgae to produce large volumes of low-cost products such as biofuels [4, 30, 31]. An understanding of what factors contribute most to these costs can suggest ways of mitigating them. The overwhelming majority of facilities, bioreactors and research for the growth of microalgae focus on the growth of planktonic cells (individual cells in liquid solution) rather than the 
growth of microalgae as biofilms. However, many microalgae species readily form biofilms [32-35], and growing microalgae as biofilms can potentially improve the efficiency and reduce the cost of microalgae production [36]. The potential advantages of growing microalgae as biofilm on internally illuminated surfaces rather than as planktonic cells include: increased biomass production, more efficient use of light energy, decreased cost of harvesting, ability to be used with turbid solutions, decreased footprint for photobioreactors, increased flexibility in the design of photobioreactors and decreased process cost.

Providing an even distribution of light in a given volume of water must deal with the fact that the intensity of light decreases with the square of the distance from the light source [37]. It is even more challenging to achieve efficient light distribution in a turbid solution of microalgae where cells closer to the light source shade cells that are below [38]. This has resulted in shallow reactors being favored for the growth of microalgae, which directly limits the volume of water used in bioreactors and raceway ponds [39]. However, if microalgae were instead grown as biofilm, combined with internal illumination [40], then light of an appropriate wavelength and intensity [41] could be evenly delivered to the biofilm, even when turbid solutions such as wastewater are used. If microalgae bioreactors were intentionally designed to grow biofilm, they would seek to maximize the surface area for the growth of biofilm and to achieve equal light distribution to all surfaces. If light energy is supplied through illuminated surfaces, the efficiency of biofilm growth can be maximized and the design of photobioreactors can be expanded [33, 41-43].

While sunlight can be used to grow microalgae, the use of electrically generated light has key advantages. Most of the energy in sunlight is not available for the growth of microalgae, as only $43 \%$ is within wavelengths that can be used in photosynthesis [37, 44, 45], and sunlight is not always available. Moreover, within those light wavelengths that can be used by photosynthetic microalgae, some wavelengths are better than others, and there is variation in which wavelengths are preferred by different species [41, 46]. This means that supplying light energy of selected wavelengths can achieve the growth of microalgae more efficiently than using sunlight directly [37, 47] and this approach has applications for growing microalgae in space as direct sunlight, especially in space, can be too intense to allow the growth of microalgae [48-50]. If the full spectrum of energy in sunlight were converted into electricity using solar, thermal or an equivalent technology, the resulting energy could be used to power light-emitting diode (LED) illumination $24 \mathrm{~h}$ per day to produce light of only selected wavelengths and at the minimum intensity required to achieve the robust growth of biofilm on surfaces that are internally illuminated. Photovoltaic cells do not harvest energy from all the wavelengths in sunlight [51], so solar-thermal energy systems are more efficient [52-54].
Electrical energy derived from sunlight, or another source of renewable energy, can then be used for the internal illumination of photobioreactors to improve process efficiency [46]. Microbial fuel cells/electrolysis cells can produce electrical energy while treating wastewater and could be used to improve the efficiency of wastewater treatment plants in the future $[55,56]$.

When microalgae are grown as planktonic cells, highintensity illumination is typically used to achieve light distribution within the bioreactor. However, high-intensity illumination can cause photoinhibition and damage microalgae $[38,41,57]$. Illumination intensities that do not cause photoinhibition do not support robust growth of planktonic microalgae cells unless exceedingly shallow photobioreactors (typically $15 \mathrm{~cm}$ liquid depth) are used [39]. However, internally illuminated surfaces can achieve robust growth of biofilm at relatively low light intensities [45]. Moreover, the growth of microalgae as biofilms simplifies biomass harvesting and dewatering because the cell density of biofilms exceeds the cell densities achieved in photobioreactors employing the harvesting and dewatering of planktonic cells $[36,58]$. The use of microalgae biofilms can potentially improve the efficiency and decrease the cost of wastewater treatment.

\section{Future use of Microalgae for Wastewater Treatment}

If microalgae are to be used in wastewater treatment, the literature can be consulted to determine which microalgae species are preferred for this application. The most common type of publication in the voluminous literature concerning the use of microalgae to produce biofuels involves descriptions of individual species of microalgae [3], the effects of nutrients [11], temperature, $\mathrm{pH}$, salinity, light intensity [2], light wavelength [59], lipid content, lipid composition, carbohydrate concentration [2], protein concentration, biodiesel/ethanol/methane/hydrogen yield [30], $\mathrm{CO}_{2}$ consumption [3], harvesting methods [31], etc. Collectively the literature demonstrates that there are myriad microalgae species/strains that are capable of growth under a wide range of environmental conditions, and each species has unique capabilities. While microalgae can be grown as pure cultures, when the application of microalgae is for the treatment of wastewater, the use of pure cultures has little relevance [29]. The complex and changing composition/concentration/volume of wastewater in most wastewater treatment facilities coupled with the goal of removing all organic and inorganic contaminants as quickly and economically as possible requires that the microbial community in wastewater treatment plants should adapt to the received wastewater, rather than trying to modify the design of the 
wastewater treatment facility to obtain optimized growth conditions for any pure microalgae culture. Just as municipal wastewater treatment facilities now must endure a start-up phase to obtain a stable microbial community capable of treating wastewater under local conditions, it will be appropriate to select for microalgae species capable of surviving under local conditions rather than trying to get specific microalgae species to grow at a given location. By adjusting the wavelength and/or the intensity of internal illumination, the growth of different microalgae species can be encouraged to enable the selective cultivation of more than one type of microalgae community that can allow for maximum contaminant removal and for the production of different bioproducts derived from microalgae. Once microalgae and bacterial cultures are identified that grow well in a given wastewater stream, it may be helpful to genetically modify some of these cultures to improve their ability to function in low oxygen environments [60], utilize light more efficiently [57] or make an alternative product [61].

While microalgae are best known for their photosynthetic capabilities to grow using light energy, many microalgae species have been shown to be capable of growing heterotrophically using organic carbon $[27,28,32]$ so that within a wastewater treatment scenario where light is supplied, microalgae can simultaneously use organic carbon and/or light energy for growth [32]. This can result in more rapid growth of microalgae and bacteria and the biodegradation of organic contaminants in wastewater [14, 62-64]. If microalgae are grown as biofilms attached to internally illuminated surfaces, then light of the appropriate intensity and wavelength can be supplied directly to microalgae cells without any risk of photoinhibition while the light supplied to the underside of the biofilm allows for continuous growth [46].

Rotating microalgae/bacterial biofilms [65-67] are described in the literature, but these examples focus on frequently removing the biofilm from the wastewater so that it can more readily be illuminated in the open air. Employing fully submerged biofilms, as suggested here, could be more efficient. High-density biofilms can be grown and used to efficiently treat wastewater to degrade organic contaminants, and remove inorganics (nitrogen, phosphorus, and metals) [32, 41, 42]. Providing LED illumination to photobioreactors in which biofilms are fully submerged in the wastewater allows for maximum treatment time of the wastewater by the biofilm, constant contaminant biodegradation and constant biomass growth.

Microalgae grown using natural sunlight grow during the daytime, but slow their growth and decrease in size due to the utilization of stored energy sources in the absence of sunlight [68]. But numerous studies have shown that microalgae can be grown using continuous illumination [38], intermittent/flashing illumination [69, 70], specific wavelength ranges [46], different light intensities [7] and as biofilms
[32]. These studies demonstrate that microalgae can be grown more productively using sunlight indirectly in the form of LED illumination rather than using sunlight directly in a photobioreactor or open pond; however, cost has limited the use of photobioreactors [7]. When the goal of photobioreactors is to grow microalgae as planktonic cells dispersed in suspension, this creates unnecessary constraints on reactor design and operation, as providing optimum illumination to all cells is challenging [57]. This has resulted in photobioreactors that have a high ratio of surface area to volume such as flat panel, tubular, plastic bag and other configurations [46].

Aerobic bacteria can biodegrade a wider range of organic contaminants, and do so more quickly than microalgae [29]. Future wastewater treatment plants that employ microalgae must accommodate the growth of both bacteria and microalgae. If microalgae are used to update the treatment of wastewater, then the growth of microalgae can produce oxygen needed by bacteria for the aerobic biodegradation of contaminants in wastewater [63], and the bacterial removal of microalgae-produced oxygen will allow for maximum rates of oxygen production [71]. Therefore, the most rapid and complete biodegradation of contaminants in wastewater will be because of the combined action of bacteria and microalgae [29]. Microalgae can be used to improve rather than replace the activated sludge process for the treatment of wastewater. This could avoid/minimize the need for aeration that is a significant operating cost for wastewater treatment facilities [63], and finding ways to decrease the energy cost of operating wastewater treatment can be a good approach to developing more sustainable processes for wastewater treatment. While it may be possible to avoid/reduce the need for external aeration through the in situ production of oxygen by microalgae, there will be increasingly strong regulatory and financial incentives to maximize $\mathrm{CO}_{2}$ fixation within the wastewater treatment process to decrease the emission of greenhouse gases [71, 72].

Research is needed to determine the best ways to maximize the biodegradation of organic contaminants in wastewater while minimizing external aeration in an environment where microalgae and internal illumination are used.

\section{Why are Biofilms Better than Planktonic Cells (a More Detailed Discussion)?}

Providing light to microalgae has been an enduring challenge both technically and economically $[38,42,73]$. Using microalgae to enhance the performance of wastewater treatment will face the same challenges of supplying light energy that currently limit the economical use of microalgae to produce biodiesel, ethanol, biogas or other products. Microalgae are most commonly grown as planktonic cells in open ponds (raceways) or in photobioreactors [4]. These planktonic cells 
are harvested by flocculation, filtration and centrifugation, and the resulting microalgae cell suspension is then dewatered to produce a more concentrated cell paste that is subsequently processed/extracted to make products. The cost of growing, harvesting and extracting microalgae currently prevents the use of microalgae to produce large volumes of low-cost products such as biofuels [31]. The cost of harvesting, concentrating and extracting lipids from microalgae biomass has been estimated to be $40-60 \%[1,74]$ of the cost of biodiesel, so that harvesting microalgae as biofilm can significantly decrease process cost.

If light energy is supplied to microalgae growing as biofilms attached to optical surfaces immersed in wastewater, then the design of reactors used for wastewater treatment will not be constrained by the difficulty of supplying external illumination, and the need to periodically shut down the system to remove biofilm that is considered as unwanted when the goal is to grow planktonic cells [45]. As mentioned above, reactors currently used for the growth of microalgae for the tertiary treatment of wastewater or for the production of biofuels often employ shallow reactors/ponds that require large areas to accommodate the volume of wastewater to be treated or the mass of biofuel desired [39]. But if light is supplied via internally illuminated surfaces and not by external illumination, then the reactors can be of any depth/dimensions so a much smaller footprint/land area is required. Wastewater treatment facilities are typically located near population centers where the cost and availability of land can be a concern. Furthermore, if wastewater treatment plants in the future will produce an array of products derived from microalgae, then additional space may be required [2, 4]. Accordingly, the use of shallow algae ponds for the treatment of wastewater will be difficult to implement at many facilities, and the most economical use of space of the wastewater treatment plant should be considered.

The treatment of large volumes of water such as in wastewater treatment plants should be rapid because the treatment time determines how large the facility should be [19]. If microalgae biofilms improve the treatment efficiency, then smaller, less expensive treatment facilities can be constructed. By using internal illumination to supply light to microalgae the surface area of the biofilm is whatever it is designed to be and the limitation is the cost of optical surfaces, cost of electricity, harvesting and processing biomass. Biofilms are well documented to be more resistant to environmental contaminants, and antibiotics, than planktonic microbial cells $[34,75]$. Accordingly, maintaining a diverse microalgae/bacterial population, growing as biofilm, will improve the stability of the wastewater treatment process. Biofilms are retained in photobioreactors until harvested and so are best suited to enable rapid treatment of the maximum volume of wastewater since they allow survival of even microbial species with generation times longer than the hydraulic retention time of the reactor [66]. The composition of the biofilm communities in microalgae-bacteria biofilm wastewater treatment facilities will not be limited to only rapidly growing species; rather, a more complex microbial communities will form, each adapted to local conditions. Moreover, the mass of biofilm that can be retained within the facility can be controlled to maximize the efficiency and effectiveness of the removal of contaminants at the fastest possible flow rates [29]. Real-time monitoring of the concentrations of contaminants and the health of biofilms will be enabled by increasingly sophisticated and inexpensive analytical techniques such as single-cell multi-isotope nanoscale secondary ion mass spectrometry [76], photo-respirometry [71] and in situ metabolism [77] and the application of growth/process modeling [39] and artificial intelligence [78].

The goal of using internally illuminated surfaces to grow microalgae biofilm requires that the surface area of the light-emitting regions should be maximized; the subsequent harvest of biofilm from these surfaces is also an important consideration [36, 63, 74]. Porous light transmitting materials of natural or man-made origin could be favorable materials for the growth of microalgae biofilm $[79,80]$ or nature-inspired structures such as leaves and trees [81, 82] may be used. The harvesting of microalgae biomass from biofilm growing on internally illuminated surfaces could be accomplished using a robotic device that is equipped with cameras/optical sensors to locate biofilm and determine its readiness for harvest, and with multiple appendages that allow the robot to move about the wastewater treatment reactor, grasp biofilm-containing structures and mechanically collect the biofilm. When the biofilm storage capacity of the robot is reached, the biofilm/biomass can then be deposited in an appropriate location for further processing and the robot can return to harvest more biofilm. The harvesting of microalgae biomass is a major component in the cost of using microalgae, and by switching from harvesting planktonic cells to harvesting biofilm (that is already as concentrated as planktonic cells after dewatering), the harvesting process can be less complex and less costly. Moreover, by automating the task of biofilm harvesting by the use of robotic devices, processing costs can be further reduced [31]. Future research is required to obtain data that will allow a meaningful discussion of process cost.

Scientists and engineers will identify how best to maximize the internally illuminated surface area within photobioreactors while simultaneously considering issues such as biomass harvesting method, wastewater treatment efficiency, maximum $\mathrm{CO}_{2}$ fixation, materials of construction and cost. There are multiple configurations that a microalgae-focused municipal resource recovery facility might take and multiple cycles of design/build/test will be required to create the most functional and economic configurations [3, 4, 81, 82]. 


\section{Wastewater Solids and Nutrient Recycling}

When wastewater is treated, the complex mixture and concentrations of contaminants present will result in the growth of a mixed culture of bacteria plus microalgae [13]. This will result in the removal of most organic matter by biodegradation and the removal of metals and nutrients (nitrogen and phosphorus) by adsorption to or incorporation in biomass $[66,83]$. Consequently the biomass recovered from the initial treatment of wastewater may contain metals and other contaminants that make it unsuitable for the recycling of the $\mathrm{N}$ and $\mathrm{P}$ as composted sludge for agricultural use. However, thermal treatment of this biomass may provide a means of beneficially recovering the nutrients while avoiding the heavy metals [7] and the biomass can be treated using anaerobic digestion to recover energy in the form of methane/biogas $[5,84]$.

After the majority of organic contaminants and metals have been removed from the wastewater, its continued treatment using internally illuminated biofilm photobioreactors will yield biomass that will be primarily microalgae, because bacteria will be increasingly at a disadvantage for growth [17]. Consequently, some of the biofilm/biomass produced in a wastewater treatment facility may be of sufficient quality so that it can be beneficially used as animal feed [17], a source of lipids for the production of biodiesel [14, 29], a source of carbohydrates for the production of ethanol [8], as a source of biopolymers for the production of bioplastics [85-87], or it can be converted to compost and used as a fertilizer [8]. Different wavelengths of light can be supplied at various locations and/or times in the waste treatment process to preferentially stimulate the growth of different microalgae to promote waste remediation and by-product synthesis. It will be important to determine the most energy efficient ways of using solar/renewable energy to support the growth of microalgae, and not simply add additional energy demand to the operation of wastewater treatment plants employing microalgae. Modern wastewater treatment plants use large amounts of energy in mixing, pumping and aerating so there are opportunities for future wastewater treatment plants to develop alternative processes that utilize less energy while achieving improved results for the treatment of wastewater.

Another factor that contributes to the variable composition of wastewater is the degree to which storm water is separated from wastewater [20]. Most sewer systems designed for the collection and treatment of wastewater experience some degree of intrusion of rainwater and floodwater. The separation of storm sewers from sewage lines is particularly important as climate change brings increasingly extreme weather, but this represents a significant infrastructure cost. This is why most wastewater treatment facilities worldwide are vulnerable to dramatic changes to the composition/concentration/volume of wastewater.
Environmental regulations and practices worldwide vary considerably, but increasingly all countries are recognizing our shared responsibilities to protect the environment of the planet. Existing wastewater treatment facilities that are successfully treating wastewater will be hesitant to adopt any new technology without data demonstrating that it will not impede their ability to treat wastewater according to local regulations [19]. This implies that any new treatment must maintain the ability to treat the volume of required wastewater with locally available reactors/equipment. Newly built wastewater treatment facilities will be more open to incorporating new technologies if their merits can be suitably demonstrated.

\section{Can Photodecarboxylase be a Catalyst for Change?}

In wastewater treatment plants the primary and secondary sludge material is increasingly treated using anaerobic digestion to biodegrade as much of the organic matter as possible into hydrocarbon gases, chiefly methane, so that the recovered gases can be used as an energy source, thereby improving the economics of wastewater treatment [19]. The volume of sludge sent to the anaerobic digester is variable depending upon the concentration of organics in wastewater, but is typically only about $1 \%$ of the volume of the wastewater [26]. Consequently, the size of the anaerobic digestion reactor is far smaller than the reactors required for the treatment of the bulk wastewater.

Anaerobic digesters are completely contained reactors that typically do not have any mechanical mixing, and are designed to collect the gas resulting from anaerobic digestion that typically uses a treatment time of weeks $[19,26]$. Any technology that can inexpensively accelerate the biodegradation of sludge and increase the amount of hydrocarbon gas collected would be a welcome innovation that could pay for itself by providing more hydrocarbon gas, and by possibly allowing anaerobic digestion reactors to be smaller, thereby decreasing the cost of equipment. A new class of photoenzyme, fatty acid photodecarboxylase, has recently been discovered that may allow for improved anaerobic digestion by the light-powered conversion of organic acids into hydrocarbon gases [88]. Fatty acid photodecarboxylases have now been shown to be present in a wide variety of algal species [89] and have also been the subject of advanced biochemical and genetic studies [90,91]. For this application, live microalgae cells are not used, rather photodecarboxylase enzyme derived from microalgae is used.

The natural role for fatty acid photodecarboxylase is in the conversion of long-chain fatty acids ( $\mathrm{C} 13$ to $\mathrm{C} 17$ fatty acids) to alkanes that are incorporated into algal cell walls. This biochemical reaction is powered by light and more 
specifically by blue light with wavelengths of 400 -to- $520 \mathrm{~nm}$ [88]. The ability to power a biochemical reaction using light energy makes it extremely interesting for industrial use, and scientists have already succeeded in modifying photodecarboxylase to metabolize low molecular weight fatty acids typically produced during anaerobic digestion; these include acetic, propionic and butyric acids resulting in their conversion to methane, ethane and propane, respectively [92].

While photodecarboxylase has been shown to be capable of catalyzing enzymatic reactions that can aid anaerobic digestion, the practical application of photodecarboxylase to wastewater treatment faces the obstacle of supplying light to a sealed reactor containing opaque and viscous sludge. A possible means of addressing this obstacle could be to immobilize photodecarboxylase enzyme to fiber optic strands. The immobilization of the enzyme to a solid support can increase the long-term stability of the enzyme [93, 94], and optical fibers can transmit light even when immersed in sludge. Optical fibers (or internally illuminated surfaces) can be connected to an external light source such as a LED that can deliver a continuous supply of light of the appropriate wavelength and intensity to power the photodecarboxylase [92]. Such a device could then be used as an accessory to anaerobic treatment reactors without requiring alterations to the existing process.

During anaerobic digestion, organic material is first biodegraded to smaller molecules such as fatty acids like acetic, propionic and butyric acids by microorganisms called acetogens. Then other microorganisms (methanogens) convert the fatty acids to methane and other gases including carbon dioxide [20]. A second type of methanogenesis involves the conversion of $\mathrm{CO}_{2}$ and hydrogen to methane. The ratelimiting step in anaerobic digestion is methanogenesis [4]. If photodecarboxylase were also present within the anaerobic digester, the rate of conversion of fatty acids to hydrocarbon gas would be accelerated [92]. This could potentially also increase the rate at which the organic material biodegrades, alter the composition of the microbial community within the anaerobic digester, increase the rate and amount of gas produced, and allow for shorter treatment times for sludge. Photobiology can not only be used to improve anaerobic digestion, but in a different application could also help to develop the technologies needed to improve the growth of microalgae as described in detail above [46].

Transforming the wastewater treatment industry to employ microalgae requires the increased availability of optical fibers (or internally illuminated surfaces) and LEDs suitable for the growth of microalgae as biofilm at low cost. The logical place to start this technology revolution is with the anaerobic digestion step in wastewater treatment, because the new technology is easier to implement at a smaller scale, after which it can be expanded to the treatment of the entire wastewater stream.

\section{Education, Jobs, Technology Innovation Hub, Public Health, Clean Water, Biofuels, Fertilizer}

Wastewater treatment plants in the future can not only be sources of clean water, renewable energy and value-added products, but can also serve as a resource for monitoring public health such as the prevalence of COVID-19 [95] or illegal and prescription drugs [96]. The concentration of drugs or infectious agents in the influent to a wastewater treatment facility can be used to monitor the status of the community, and by sampling wastewater at various locations in the wastewater collection system, it is possible to determine neighborhoods most/least affected. These data can be used to allocate public health resources [95]. The wastewater treatment plant of the future can provide excellent educational/training opportunities, as many technologies will be utilized including civil engineering, electrical engineering, robotics, biology, analytical chemistry and public health surveillance. The conversion of wastewater treatment plants to resource production centers will require major challenges and technology innovation as a constant process. Wastewater treatment facilities associated with a university could provide an ideal site for technology development as well as for training personnel needed to operate the many wastewater treatment facilities that each country needs.

\section{Summary}

Recent progress in understanding the biology of photosynthetic microorganisms could greatly benefit wastewater treatment. Wastewater is increasingly viewed as a resource and photobiology can help. Methane and other hydrocarbon gases can be obtained from the anaerobic digestion of organic waste, nutrients such as nitrogen and phosphate can be removed from wastewater as biomass and recycled for agricultural use as compost, and clean fresh water can be derived from wastewater. The use of microalgae in wastewater treatment is not common, but is currently used in wastewater treatment as a polishing step to remove nutrients. Nutrient removal depends, however, upon the growth of microalgae (and microbial) biomass, and the complete removal of nutrients is difficult to accomplish on the scale needed by the wastewater treatment industry. The easiest application of microalgae in wastewater treatment is to improve the anaerobic digestion process. Then, as photobiology technology matures, the widespread use of microalgae to treat the entirety of wastewater will become increasingly economical. A new class of light-powered enzymes has been found that can convert organic acids to alkanes: fatty acid photodecarboxylase from algae. This photoenzyme only requires light energy to convert organic acids such as acetic, propionic and butyric 
acid to the gas phase hydrocarbons methane, ethane and propane, respectively. Fiber optic strands can be modified by attaching the photoenzyme to its surfaces, after which the fiber optic strands can be placed inside an anaerobic digester and provided with a constant light source. This will increase the amount of hydrocarbon gases beneficially recovered and will likely result in an increased rate of waste degradation.

If microalgae are to be used to treat the entirety of wastewater, microalgal biomass can be grown as biofilm attached to optical fibers/surfaces. In this way, better microalgae growth and nutrient removal can be achieved, and the biomass can be harvested more economically as a biofilm than as planktonic microalgae cells. The future applications of photobiology to the wastewater treatment industry are as vast as our imaginations.

Acknowledgements Helpful discussions and text editing were provided by Dr. Mark R. Chandler Ph.D. Technology Management and Dr. Benjamin C. Stark Ph.D. Microbiology.

\section{References}

1. Han, S.-F.; Jin, W.-B.; Tu, R.-J.; Wu, W.-M.: Biofuel production from microalgae as feedstock: current status and potential. Crit. Rev. Biotechnol. 35(2), 255-268 (2016). https://doi.org/10.3109/ 07388551.835301

2. Khan, M.I.; Shin, J.H.; Kim, J.-D.: The promising future of microalgae: current status, challenges, and optimization of a sustainable and renewable industry for biofuels, feed, and other products. Microb. Cell Factories. 17, 36 (2018). https://doi.org/10.1186/ s12934-018-0879-x

3. Hossain, N.; Mahlia, T.M.I.: Progress in physico-chemical parameters of microalgae cultivation for biofuel production. Critic. Rev. Microbiol. (2019). https://doi.org/10.1080/07388551.2019. 1624945

4. Kumar, M.; Sun, Y.; Rathour, R.; Pandey, A.; Thakur, I.S.; Tsang, C.W.: Algae as potential feedstock for the production of biofuels and value-added products: Opportunities and challenges. Sci. Total Environ. 716, 137116 (2020). https://doi.org/10.1016/j.scitotenv. 2020.137116

5. Hughes, A.D.; Kelly, M.S.; Black, K.D.; Stanley, M.S.: Biogas from macroalgae: Is it time to revisit the idea? Biotechnol. Biofuels. 2012(5), 86 (2012). https://doi.org/10.1186/1754-6834-5-86

6. Kilbane, J.J., II.: Future applications of biotechnology to the energy industry. Front. Microbiol. 7, 86 (2016). https://doi.org/10.3389/ fmicb.2016.00086(2016)

7. Johnson, T.J.; Katuwal, S.; Anderson, G.A.; Gu, L.; Zhou, R.; Gibbons, W.R.: Photobioreactor cultivation strategies for microalgae and cyanobacteria. Biotechnol. Progress (2018). https://doi.org/10. 1002/btpr.2628

8. Kalra, R.; Gaur, S.; Goel, M.: Microalgae bioremediation: a perspective towards wastewater treatment along with industrial carotenoids production. J. Water Process Eng. (2020). https://doi. org/10.1016/j.jwpe.2020.101794

9. Chamkalani, A.; Zendehboudi, S.; Rezaei, N.; Hawboldt, K.: A critical review on life cycle analysis of algae biodiesel: current challenges and future prospects. Renew. Sustain. Energy Rev. 134, 110143 (2020). https://doi.org/10.1016/j.rser.2020.110143

10. Dasan, Y.K.; Lam, M.K.; Yusup, S.; Lim, J.W.; Lee, K.T.: Life cycle evaluation of microalgae biofuels production: Effect of culti- vation system on energy, carbon emission and cost balance analysis. Sci. Total Environ. 688, 112-128 (2019). https://doi.org/10.1016/ j.scitotenv.2019.06.181

11. Jegathese, S.J.P.; Farid, M.: Microalgae as a renewable source of energy: A niche opportunity. J. Renew. Energy 2014, 430203 (2014). https://doi.org/10.1155/2014/430203

12. Dalvi, V.; Chawla, P.; Malik, A.: Year-long performance assessment of an on-site pilot scale (100L) photobioreactor on nutrient recovery and pathogen removal from urban wastewater using native microalgal consortium. Algal Res. 55, 102228 (2021). https://doi. org/10.1016/j.algal.2021.102228

13. Oswald, W.J.; Gotaas, H.B.: Photosynthesis in sewage treatment. Am. Soc. Civil Eng. 122, 73-105 (1957)

14. Jeong, D.; Jang, A.: Exploration of microalgal species for simultaneous wastewater treatment and biofuel production. Environ. Resour. 188,109772 (2020). https://doi.org/10.1016/j.envres.2020. 109772

15. Tam, N.F.Y.; Wong, Y.S.: Wastewater nutrient removal by Chlorella pyrenoidosa and sp. Environ. Pollut. 58, 19-34 (1989)

16. Jones, E.R.; van Vliet, M.T.H.; Qadir, M.; Bierkens, M.F.P.: Country-level and gridded estimates of wastewater production, collection, treatment and resuse. Earth Syst. Sci. Data 13(2), 237-254 (2021). https://doi.org/10.5194/essd-13-237-2021

17. Guldhe, A.; Kumari, S.; Ramanna, L.; Ramsundar, P.; Singh, P.; Rawat, I.; Bux, F.: Prospects, recent advancements and challenges of different wastewater streams for microalgal cultivation. J. Environ. Manag. 203, 299-315 (2017). https://doi.org/10.1016/ j.jenvman.2017.08.012

18. Vaneeckhaute, C.: Integrating resource recovery process and watershed modelling to facilitate decision making regarding biofertilizer production and application. Clean Water 4, 15 (2021). https://doi.org/10.1038/s41545-021-00105-6

19. Sikosana, M.L.; Sikhwiuhilu, K.; Moutloali, R.; Madyira, D.M.: Municipal wastewater treatment technologies: a review. Procedia Manuf. 35, 1018-1024 (2019). https://doi.org/10.1016/j.promfg. 2019.06.051

20. Abdel-Raouf, M.E.; Maysour, N.E.; Farag, R.K.; Abdul-Raheim, A.R.M.: Wastewater treatment methodologies, review article. Int. J. Environ. Agric. Sci. 3, 018 (2019)

21. Bak, J.; Barbusinski, K.; Thomas, M.: Review of methods for assessing the impact of WWTPs on the natural environment. Clean Technol. 3, 98-122 (2021). https://doi.org/10.3390/ cleantechnol3010007

22. Breitberg, D.; Levin, L.A.; Oschlies, A.; Gregoire, M.; Garcon, V.; Gutierrez, D.: Declining oxygen in the global ocean and coastal waters. Science (2018). https://doi.org/10.1126/science.aam7240

23. Gupta, G.V.M.; Jyothibabu, R.; Ramu, C.V.; Reddy, A.Y.; Balachandran, K.K.; Sudheesh, V.; Kumar, S.; Chari, N.V.H.K.; Bepari, K.F.; Marathe, P.H.; Reddy, B.B.; Vijayan, A.K.: The world's largest coastal deoxygenation zone is not anthropogenically driven. Environ. Res. Lett. 16, 054009 (2021). https://doi. org/10.1088/1748-9326/abe9eb

24. Oschlies, A.: A committed fourfold increase in ocean oxygen loss. Nat. Commun. (2021). https://doi.org/10.1038/s41462-02122584-4

25. Sas, E.; Hennequin, L.M.; Fremont, A.; Jerbi, A.; Legault, N.; Lamontagne, J.; Fagoaga, N.; Serrazin, M.; Hallett, J.P.; Fennell, P.S.; Barnabe, S.; Labrecque, M.; Brereton, N.J.B.; Pitre, F.E.: Biorefinery potential of sustainable municipal wastewater treatment using fast growing willow. Sci. Total Environ. 792, 148146 (2021). https://doi.org/10.1016/j.scitotenv.2021.148146

26. Abusoglu, A.; Demir, S.; Kanoglu, M.: Thermoeconomic assessment of a sustainable municipal wastewater treatment system. Renew. Energy 48, 424-435 (2012). https://doi.org/10.1016/j. renene.2012.06.005 
27. Fan, J.; Cao, L.; Gao, C.; Chen, Y.; Zhang, T.C.: Characteristics of wastewater treatment by Chlorella sorokiniana and comparison with activated sludge. Water Sci. Technol. 80(5), 892-901 (2019). https://doi.org/10.2166/wst.2019.329

28. Trentin, G.; Bertucco, A.; Sforza, E.: Mixotrophy in Synechocystis $\mathrm{sp}$. for treatment of wastewater with high nutrient content effect of CO2 and light. Bioprocess Biosyst. Eng. 42, 1661-1669 (2019). https://doi.org/10.1007/s00449-019-02162-1

29. Khoo, K.S.; Chia, W.Y.; Chew, K.W.; Show, P.L.: Microalgalbacterial consortia as future prospect in wastewater bioremediation, environmental management and bioenergy production. Indian J. Microbiol. 61(3), 262-269(2021). https://doi.org/10.1007/s12088021-00924-8

30. De Souza, M. P.; Hoetz, M.; Gressler, P. D.; Benitez, L. B.; Schneider, R. C. S.: Potential microalgal bioproducts General perspectives and main challenges. Waste Biomass Valorization. https://doi.org/ 10.1007/s12649-018-0253-6

31. Anathi, V.; Balaji, P.; Sindhu, R.; Kim, S.H.; Pugazhendi, A.; Arun, A.: A critical review on different harvesting techniques for algal based biodiesel production. Sci. Total Environ. 780, 146457 (2021). https://doi.org/10.1016/j.scitotenv.2021.146467

32. Roostaei, J.; Zhang, Y.; Gopalakrishnan, K.; Ochocki, A.J.: Mixotrophic microalgae biofilm: a novel algae cultivation strategy for improved productivity and cost-efficiency of biofuel feedstock production. Scientific Rep. 8, 12528 (2018). https://doi.org/10. 1038/s41598-018-31016-1

33. Kim, S.; Kim, D.; Ryu, B.-G.; Chang, Y.K.: Design optimization of large-scale attached cultivation of Ettlia sp to maximize biomass production based on simulation of solar irradiation. Appl. Energy. 279, 115802 (2020). https://doi.org/10.1016/j.apenergy. 2020.115802

34. Zhang, Q.; Wang, L.; Yu, Z.; Zhou, T.; Gu, Z.; Huang, Q.; Xiao, B.; Zhou, W.; Ruan, R.; Liu, Y.: Pine sawdust as algal biofilm biocarrier for wastewater treatment and algae-based byproduct production. J. Clean. Prod. 256, 120449 (2020). https://doi.org/10.1016/j.clepro. 2020.120449

35. Makaroglov, G.; Marakas, H.; Fodelianakis, S.; Gikas, P.: Optimization of biomass production from Stichococccus sp biofilms coupled to wastewater treatment. Biochem. Eng. J. 169, 107964 (2021). https://doi.org/10.1016/j.bej.2021.107964

36. Ferreira, J.; de Assis, L.R.; de Sousa Oliveira, A.P.; de Siqueira Castro, J.; Calijuri, M.L.: Innovative microalgae biomass harvesting methods: Technical feasibility and life cycle analysis. Sci. Total Environ. 746, 140939 (2020). https://doi.org/10.1016/j.scitotenv. 2020

37. Ooms, M.D.; Dinh, C.T.; Sargent, E.H.; Sinton, D.: Photon management for augmentated photosynthesis. Nat. Commun. (2016). https://doi.org/10.1038/ncomms12699

38. Ogbonna, J.C.; Tanaka, H.: Light requirement and photosynthetic cell cultivation: development of processes for efficient light utilization in photobioreactors. J. Appl. Phycol. 12, 207-218 (2000)

39. Sun, N.; Skaggs, R.L.; Wigmosta, M.S.; Coleman, A.M.; Huesemann, M.H.; Edmondson, S.J.: Growth modeling to evaluate alternative cultivation strategies to enhance national microalgal biomass production. Algal Res. 49, 101939 (2020). https://doi.org/ 10.1016/j.algal.2020.101939

40. Ooms, M.D.; Graham, P.J.; Nguyen, B.; Sargent, E.H.; Sinton, D.: Light dilution via wavelength management for efficient highdensity photobioreactors. Biotechnol. Bioeng. (2017). https://doi. org/10.1002/bit.26261

41. Li, Y.; Li, L.; Liu, J.; Qin, R.: Light absorption and growth response of Dunaliella under different light qualities. J. Appl. Phycol. 32, 1041-1052 (2020). https://doi.org/10.1007/s10811-020-02057-9

42. Sivakaminathan, S.; Wolf, J.; Yarnold, J.; Roles, J.; Ross, I.L.; Stephens, E.; Henderson, G.; Hankamer, B.: Light guide systems enhance microalgae production efficiency in outdoor high rate ponds. Algal Res. 47, 101846 (2020). https://doi.org/10.1016/j. algal.2020.101846

43. Sun, Y.; Yu, G.; Xiao, G.; Duan, Z.; Dai, C.; Hu, J.; Wang, Y.; Yang, Y.; Jiang, X.: Enhancing $\mathrm{CO} 2$ photo-biochemical conversion in a newly-designed attached photobioreactor characterized by stacked horizontal planar waveguide modules. Sci. Total Environ. 760, 144041 (2021). https://doi.org/10.1016/j.scitotenv.2020. 144041

44. Cho, C.; Nam, K.; Kim, G.-Y.; Seo, Y.H.; Hwang, T.G.; Seo, J.-W.; Kim, J.P.; Han, J.-I.; Lee, J.-Y.: Multi-bandgap solar energy conversion via combination of microalgal photosynthesis and spectrally selective photovoltaic cell. Scientific Rep. 9, 18999 (2019). https:// doi.org/10.1038/s41598-019-55358-6

45. Wondraczek, L.; Grundler, A.; Reupert, A.; Wondraczak, K.; Schmidt, M.A.; Pohnert, G.; Nolte, S.: Biomimetic light dilution using side-emitting optical fiber for enhancing the productivity of microalgae reactors. Scientific Rep. 9, 9600 (2019). https://doi.org/ 10.1038/s41598-019-45955-w

46. Sero, E.T.; Siziba, N.; Bunhu, T.; Shoko, R.; Jonathan, E.: Biophotonics for improving algal photobioreactor performance: a review. Energy Res. 2020, 1-22 (2020). https://doi.org/10.1002/er.5059

47. Raeisossadati, M.; Moheimani, N.R.; Parlevliet, D.: Luminescent solar concentrator panels for increasing the efficiency of mass microalgal production. Renew. Sustain. Energy Rev. 101, 47-59 (2019). https://doi.org/10.1016/j.rser.2018.10.029

48. Janssen, P.J.D.; Lambreva, M.D.; Plumere, N.; Bartolucci, C.; Antonacci, A.; Buonasera, K.; Frese, R.N.; Scognamiglio, V.; Rea, G.: Photosynthesis at the forefront of a sustainable life. Front. Chem. 2, 36 (2014). https://doi.org/10.3389/fchem.2014.00036

49. Wagner, I.; Steinweg, C.; Posten, C.: Mono- and dichromatic LED illumination leads to enhanced growth and energy conversion for high-efficiency cultivation of microalgae for application in space. Biotechnol. J. (2016). https://doi.org/10.1002/biot.201500357

50. Fahrion, J.; Mastroleo, F.; Dussap, C.-G.; Leys, N.: Use of photobioreactors in regenerative life support systems for human space exploration. Front. Microbiol. (2021). https://doi.org/10. 3389/fmicb.2021.699525

51. Diwania, S.; Agrawai, S.; Siddiqui, A.S.; Singh, S.: Photovoltaicthermal (PV/T) technology: a comprehensive review on applications and its advancement. Int. J. Energy Environ. Eng. 11, 33-54 (2020)

52. Chen, Q.; Wang, Y.; Zhang, J.; Wang, Z.: The knowledge mapping of concentrating solar power development based on literature analysis technology. Energies. https://doi.org/10.3390/ en13081988 (2020)

53. Codd, D. S.; Escarra, M. D.; Riggs, B.: Solar cogeneration of electricity with high-temperature process heat. Cell Rep. Phys. Sci. https://doi.org/10.1016/j.xcrp.2020.100135 (2020)

54. Schiniger, F.; Thonig, R.; Resch, G.; Lilliestam, J.: Making the sun shine at night: comparing the cost of dispatchable concentrating solar power and photovoltaics with storage. Energy Sour. Part B: Econ. Plan. Policy. https://doi.org/10.1080/15567249.2020. 1843565 (2020)

55. Kaleekkal, N. J.; Mural, P. K. S; Vigneswara, S.; Ghosh, U. (eds.): Sustainable Technologies for water and wastewater treatment. CRC Press, Boca Raton FL, ISBN 9780367510374 (2021)

56. Sapireddy, V.; Katuri, K.P.; Ali, M.; Saikaly, P.: Competition of two highly specialized and efficient acetoclastic electroactive bacteria for acetate in biofilm anode of microbial electrolysis cell. Biofilms Microb (2021). https://doi.org/10.1038/s41522-021-00218-3

57. Fu, W.; Chaiboonchoe, A.; Khraiwesh, B.; Sultana, M.; Jaiswal, A.: Intracellular spectral recompositioning of light enhances algal photosynthetic efficiency. Sci. Adv. 3(9), e1603096 (2017). https:// doi.org/10.1126/sciadv.1603096 
58. Gross, M. A.: Development and optimization of biofilm based algae cultivation. Ph.D. Thesis Iowa State University https://lib.dr.iastate. edu/etd/14850 (2015)

59. Yim, S.-K.; Ki, D.-W.; Doo, H.-S.; Kim, H.; Kwon, T.-H.: Internally illuminated photobioreactor using a novel type of light-emitting diode (LED) bar for cultivation of Arthrospira platensis. Biotechnol. Bioprocess Eng. 21, 767-776 (2016). https://doi.org/10.1007/ s12257-016-0428-6

60. Kunkel, S.A.; Pagilla, K.R.; Stark, B.C.: Engineering of Nitrosomonas europaea to express Vitreoscilla hemoglobin enhances oxygen uptake and conversion of ammonia to nitrite. AMB Express 5(1), 1-8 (2015). https://doi.org/10.1186/s13568-015-0135-2

61. Durall, C.; Kukil, K.; Hawkes, J.A.; Albergati, A.; Lindblad, P.; Lindberg, P.: Production of succinate by engineered strains of Synechocystis PCC6803 overexpressing phosphoenolpyruvate carboxylase and a glyoxylate shunt. Microb. Cell Factories. 20, 39 (2021). https://doi.org/10.1186/s12934-021-01529-y

62. de Assis, L. R.; Calijuri, M. L.; de Aguiar do Couto, E.; Assemany, P.P.: Microalgal biomass production and nutrients removal from domestic sewage in a hybrid high-rate pond with biofilm reactor. Ecol. Eng. 106:191-199. https://doi.org/10.1016/j.ecoleng.2017. 05.040 (2017)

63. Abiusi, F.; Wijffels, R.H.; Janssen, M.: Doubling of microalgae productivity by oxygen balanced mixotrophy. ACS Sustain. Chem. Eng. 8(15), 6065-6074 (2020). https://doi.org/10.1021/ acssuschemeng.0c00990

64. Brockmann, D.; Gerand, Y.; Park, C.: Wastewater treatment using oxygenic photogranule-based process has lower environmental impact than conventional activated sludge process. Bioresour. Technol. (2020). https://doi.org/10.1016/j.biortech.2020.124204

65. Woolsey, P. A.: Rotating algal biofilm reactors: Mathematical modeling and lipid production. M. S. Thesis Utah State University https://digitalcommons.usu.edu/etd/1107 (2011)

66. Zhao, X.; Kumar, K.; Gross, M.A.; Kunetz, T.E.; Wen, Z.: Evaluation of revolving biofilm reactors for nutrients and metals removal from sludge thickening supernatant in a municipal wastewater treatment facility. Water Res. 143, 467-478 (2018). https://doi.org/10. 1016/j.watres.2018.07.001

67. Morales, M.; Bonnefond, H.; Bernard, O.: Rotating algal biofilm versus planktonic cultivation: LCA perspective. J. Clean. Prod. 257, 120547 (2020). https://doi.org/10.1016/j.clepro.2020.120547

68. Ogbonna, J.; Soejima, T.; Tanaka, H.: An integrated solar and artificial light system for internal illumination of photobioreactors. J. Biotechnol. 70(1-3), 289-297 (1999). https://doi.org/10.1016/ s0168-1656(99)00081-4

69. Xue, S.; Zhang, Q.; Wu, X.; Yan, C.; Cong, W.: A novel photobioreactor structure using optical fibers as inner light source to fulfill flashing light effects of microalgae. Bioresour. Technol. 138, 141-147 (2013). https://doi.org/10.1016/j.biortech.2013.03.156

70. Abu-Ghosh, S.; Fixler, D.; Dubinsky, Z.; Iluz, D.: Continuous background light significantly increases flashing-light enhancement of photosynthesis and growth of microalgae. Bioresour. Technol. 187, 144-148 (2015). https://doi.org/10.1016/j.biortech.2015.03.119

71. Rossi, S.; Sforza, E.; Pastore, M.; Belluesi, M.; Casagli, F.; Marazzi, F.; Ficara, E.: Photo-respirometry to shed light on microalgaebacteria consortia: a review. Rev. Environ. Sci. Biotechnol. 19, 43-72 (2020). https://doi.org/10.1007/s11157-020-09524-2

72. Goli, A.; Shamiri, A.; Talaiekhozani, T.; Eshtiaghi, N.; Aghamohammadi, N.; Aroua, M.K.: An overview of biological processes and their potential for CO2 capture. J. Environ. Manag. (2016). https://doi.org/10.1016/j.envman.2016.08.054

73. Zijffers, J.W.F.; Janssen, M.; Tramper, M.; Wijffels, R.H.: Design process of an area-efficient photobioreactor. Marine Biotechnol. 10, 404-415 (2008)

74. Fasaei, F.; Bitter, J.H.; Slegers, P.M.; van Broxtel, A.J.B.: Technoeconomic evaluation of microalgae harvesting and dewatering systems. Algal Res. 31, 347362 (2018). https://doi.org/10.1016/ j.algal.2017.11.038

75. Gross, M.; Wen, Z.: Yearlong evaluation of performance of a pilotscale revolving algal biofilm (RAB) cultivation system. Bioresour. Technol. 171, 50-58 (2014). https://doi.org/10.1016/j.biortech. 2014.08.052

76. Dekas, A.E.; Parada, A.E.; Mayali, X.; Fuhrman, J.A.; Wollard, J.; Weber, P.K.; Pett-Ridge, J.: Characterizing chemoautotrophy and heterotrophy in marine Archaea and bacteria with single-cell multiple-isotope Nano SIP. Front. Microbiol. (2019). https://doi. org/10.3389/fmicb.2019.02682

77. Qubit Systems: CISME: Community In Situ Metabolism https:// www.qubitbiology.com/products/aquatic-respiration-and photosynthesis (2021)

78. Mowbray, M.; Savage, T.; Wu, C.; Song, Z.; Cho, B.A.; RioChanona, E.A.D.; Zhang, D.: Machine learning for biochemical engineering: a review. Biochem. Eng. J. 172, 108054 (2021). https://doi.org/10.1016/j.bej.2021.108054

79. Jacob, A.; Bucharsky, E.C.; Schell, K.G.: The application of transparent glass sponges for improvement of light distribution in photobioreactors. J. Bioprocess. Biotech. 2, 113 (2012). https:// doi.org/10.4172/2155-9821.1000113

80. Podola, B.; Li, T.; Melkonian, M.: Porous substrate bioreactors: a paradigm shift for algal biotechnology? Trends Biotechnol. 35(2), 121-132 (2017)

81. Coppens, M.-O.: A nature-inspired approach to reactor and catalysis engineering. Current Opin. Chem. Eng. 1, 1-9 (2012). https:// doi.org/10.1016/j.coche.2012.03.002

82. Snow, T.: Ecosystem metabolisms and functions-an eco-literacy framework and model for designers. Form Akademisk (2020). https://doi.org/10.7577/formakademisk.3370

83. Ubando, A.T.; Africa, A.D.M.; Maniquiz-Redillas, M.C.; Culaba, A.B.; Chang, J.-S.: Microalgal biosorption of heavy metals: a comprehensive bibliometric review. J. Hazard. Mater. 402, 123431 (2020). https://doi.org/10.1016/j.jhazmat.2020.123431

84. Milledge, J.J.; Nielsen, B.V.; Maneein, S.; Harvey, P.J.: A brief review of anaerobic digestion of algae for bioenergy. Energies 12, 1166 (2019). https://doi.org/10.3390/en12061166

85. Koch, M.; Bruckmoser, J.; Scholl, J.; Hauf, W.; Rieger, B.; Forchhammer, K.: Maximizing PHB content in Synechocystis sp PCC 6803: a new metabolic engineering strategy based on the regulator PirC. Microb. Cell Factories 19, 231 (2020). https://doi.org/10. 1186/s12934-020-01491-1

86. Leong, H.Y.; Chang, C.-K.; Khoo, K.S.; Chou, K.W.; Chia, S.R.; Lim, J.W.; Chang, J.-T.; Show, P.L.: Waste biorefinery towards a sustainable circular bioeconomy: a solution to global issues. Biotechnol. Biofuels 14, 87 (2021). https://doi.org/10.1186/ s13068-021-01939-5

87. Lutzu, G.A.; Ciurli, A.; Chiellini, C.; DiCaprio, F.; Concas, A.; Dunford, N.: T: Latest developments in wastewater treatment and biopolymer production by microalgae. J. Environ. Chem. Eng. 9(1), 104926 (2021). https://doi.org/10.1016/J.jece.2020.104926

88. Sorigue, D.; Legerer, B.; Cuine, S.; Blangy, S.; Billon, E.; Richaud, P.: An algal photoenzyme converts fatty acids to hydrocarbons. Science 357(6354), 903-907 (2017). https://doi.org/10.1126/science. aan6349

89. Alaksenko, V.A.; Anand, D.; Remeeva, A.; Nazarenkov, V.; Gordeliy, V.; Jaeger, K.E.; Krauss, U.; Gushchin, I.: Phylogeny and structure of fatty acid photodecarboxylases and glucose-methanolcholine oxidoreductases. Catalysts 10(9), 1072 (2020). https://doi. org/10.3390/catal10091072(2020)

90. Hayes, D.J.; Lakavath, B.; Hardman, S.J.O.; Sakuma, M.; Hedison, T.M.; Scrutton, N.G.: Photochemical mechanism of light-driven fatty acid photodecarboxylase. ACS Catal. 10(12), 6691-6696 (2020). https://doi.org/10.1021/acscatal.0c01684 
91. Trisriviirat, D.; Hughes, J.M.X.; Hoeven, R.; Faulkner, M.; Toogood, H.; Chaiyen, P.; Scrutton, N.S.: Promoter engineering for microbial bio-alkane gas production. Synth. Biol. (2020). https:// doi.org/10.1093/synbio/ysaa022

92. Amer, M.; Toogood, H.; Scrutton, N.S.: Engineering nature for gaseous hydrocarbon production. Microb. Cell Factories 19, 209 (2020). https://doi.org/10.1186/s12934-020-01470-6

93. Guzik, U.; Hupert, K.; Kocurek, D.; Wojcieszynska, J.: Immobilization as a strategy for improving enzyme properties: application to oxidoreductases. Molecules 19, 8995-9018 (2014). https://doi. org/10.3390/molecules 19078995

94. Zhou, Y.-B.; Cao, J.-W.; Sun, X.-B.; Wang, H.; Gao, D.-Y.; Li, Y.-N.; Wu, K.-Y.; Wang, J.-K.; Qian, G.-Y.; Wang, Q.: Enhanced stability of a rumen-derived xylanase using SpyTag/SpyCatcher cyclization. World J. Microbiol. Biotechnol. 36, 33 (2020). https:// doi.org/10.1007/s11274-020-2809-4
95. Farkas, K.; Hillary, L.S.; Malhamm, S.K.; McDonald, J.E.; Jones, D.L.: Wastewater and public health: the potential of wastewater surveillance for monitoring covid-19. Curr. Opin. Environ. Sci. Health. 17, 14-20 (2020). https://doi.org/10.1016/j.coesh.2020.06. 001

96. Daughton, C.G.: Monitoring wastewater for assessing community health: sewage chemical-information mining (SCIM). Sci. Total Environ. 619-620, 748-764 (2018). https://doi.org/10.1016/ j.scitotenv.2017.11.102 